\title{
Participation of the Prostaglandins in the Control of Renal Blood Flow during Acute Reduction of Cardiac
}

\section{Output in the Dog}

\author{
Juan A. Oliver, Robert R. Sciacca, John Pinto, and Paul J. Cannon, \\ Department of Medicine, College of Physicians is Surgeons, \\ Columbia University, New York 10032
}

A B STRACT To determine whether renal prostaglandins participate in the regulation of renal blood flow during acute reduction of cardiac output, cardiac venous return was decreased in 17 anesthetized dogs by inflating a balloon placed in the thoracic inferior vena cava. This maneuver decreased cardiac output from $3.69 \pm 0.09$ liters $/$ min $($ mean $\pm S E M)$ to $2.15 \pm 0.19$ liters $/ \mathrm{min}(P<0.01)$ and the mean arterial blood pressure from $132 \pm 4$ to $111 \pm 5 \mathrm{~mm} \mathrm{Hg}(P<0.01)$ and increased total peripheral vascular resistance from $37.6 \pm 2.5$ to $57.9 \pm 4.8$ arbitrary resistance units $(\mathrm{RU})(P$ $<0.01)$. In marked contrast, only slight and insignificant decreases in the renal blood flow from $224 \pm 16$ to $203 \pm 19 \mathrm{ml} / \mathrm{min}$ and renal vascular resistance from 0.66 \pm 0.06 to $0.61 \pm 0.05$ arbitrary resistance units $(\mathrm{ru})$ were observed during inflation of the balloon. Concomitant with these hemodynamic changes, plasma renin activity and plasma norepinephrine concentration increased significantly in both the arterial and renal venous bloods. Plasma concentration of prostaglandin $E_{2}$ in renal venous blood increased from $34 \pm 6$ to $129 \pm 24$ $\mathrm{pg} / \mathrm{ml}(P<0.01)$. The subsequent administration of indomethacin or meclofenamate had no significant effect on mean arterial pressure, cardiac output, and total peripheral vascular resistance, but reduced renal blood flow from $203 \pm 19$ to $156 \pm 21 \mathrm{ml} / \mathrm{min}(P<0.01)$ and increased renal vascular resistance from $0.61 \pm 0.05$ to $1.05 \pm 0.21$ ru $(P<0.01)$. Simultaneously, the plasma concentration of prostaglandin $\mathrm{E}_{2}$ in renal venous blood fell from $129 \pm 24$ to $19 \pm 3 \mathrm{pg} / \mathrm{ml}(P<0.01)$. Administration of indomethacin to five dogs without prior obstruction of the inferior vena cava had no effect upon renal blood flow or renal vascular resistance. The results indicate that acute reduction of cardiac output enhances renal renin secretion and the activity of the

Received for publication 7 April 1980 and in revised form 20 August 1980. renal adrenergic nerves as well as renal prostaglandin synthesis without significantly changing renal blood flow or renal vascular resistance. Inhibition of prostaglandin synthesis during acute reduction of cardiac output results in an increased renal vascular resistance and reduced renal blood flow. Accordingly, that data provide evidence that renal prostaglandins counteract in the kidney the vasoconstrictor mechanisms activated during acute reduction of cardiac output.

\section{INTRODUCTION}

Acute decreases in cardiac output are accompanied by substantial increases in total peripheral vascular resistance. In patients with congestive heart failure with edema, Merrill (1) demonstrated reduced renal plasma flow. Although renal blood flow may also decrease in acute heart failure (2), studies by Levy and Berne (3) demonstrated that the renal circulation does not participate to the same extent as the rest of the circulation in the vasoconstrictor response. During acute decreases in cardiac output renal blood flow fell only slightly or did not change $(3,4)$. More importantly, the rise in the renal vascular resistance was considerably less than the rise in total peripheral vascular resistance (3). These results have been confirmed in elegant studies in unanesthetized dogs by White et al. (5) and Higgins et al. (6). These workers showed that the reduction of cardiac output by bradycardia (5), or by lowering venous return to the heart (6) induced marked vasoconstriction of the mesenteric and iliac beds, but failed to induce renal vasoconstriction.

The absence of an increase in renal vascular resistance during acute heart failure is noteworthy since the renin-angiotensin and sympathetic nervous systems are known to be activated in this condition (7-9). The high peripheral vascular resistance during acute heart 
failure is, at least in part, mediated by angiotensin II, a potent renal vasoconstrictor; the administration of the converting enzyme inhibitor during heart failure reduces total peripheral vascular resistance and blood pressure $(7,8)$. The sympathetic nervous system is also likely to participate in the maintenance of the arterial pressure since elevated levels of plasma norepinephrine have been found in patients with heart failure (9).

Work by several laboratories has recently demonstrated that regulation of renal blood flow results from the interplay of vasoconstrictor and vasodilator factors. In particular, prostaglandins are known to be involved in renal blood flow control in a variety of conditions in which the renin-angiotensin system is activated. Although inhibition of the synthesis of prostaglandins has little or no effect upon renal blood flow during control conditions $(10-12)$, it elicits or augments the reductions of renal blood flow that occur during hemorrhagic hypotension $(13,14)$, sodium depletion (15), and in patients with cirrhosis and ascitis (16).

The purpose of the present study was to determine whether the renal prostaglandins are involved in the maintenance of renal blood flow during an acute decrease of cardiac output. The experiments were carried out in anesthetized dogs in which cardiac output was decreased by preventing cardiac venous return by means of an inflatable balloon placed in the thoracic inferior vena cava. Simultaneous measurements of arterial and renal venous concentrations of prostaglan$\operatorname{din} \mathrm{E}_{2}\left(\mathrm{PGE}_{2}\right)^{1}$ and of plasma renin activity, as well as renal blood flow and systemic hemodynamics, were performed in control conditions, during acute heart failure and following the administration of inhibitors of prostaglandin synthesis.

\section{METHODS}

Experimental preparation. The experiments were performed in 22 mongrel dogs of either sex weighing an average of $26.2 \pm 0.9 \mathrm{~kg}$ (mean \pm SEM) that were fed a normal chow diet that provided a sodium intake of $80-100 \mathrm{meq} / \mathrm{d}$. Anesthesia was induced with sodium pentobarbital $(30 \mathrm{mg} / \mathrm{kg}$ i.v. $)$ and maintained with periodic additional administration. After anesthesia, each animal received an infusion of Ringer's lactate equal to $4 \%$ of the body weight, followed by a sustaining infusion of $0.2 \mathrm{ml} / \mathrm{kg}$ per min for the remainder of the experiment. After cannulation of the trachea, the dogs were mechanically ventilated. Through a femoral artery, a catheter was introduced into the aorta for blood pressure measurements (P23Db Statham transducer [Statham Instruments, Inc., Oxnard, Calif.] and Grass polygraph recorder [Grass Instrument Co., Quincy, Mass.]) and for arterial blood collections. Via the right jugular vein, a catheter was introduced into the right atrium for the administration of indocyanine dye solution. Cardiac output was determined as

${ }^{1}$ Abbreciations used in this paper: $\mathrm{PGE}_{2}$, prostaglandin $\mathrm{E}_{2}$; PGSI, prostaglandin synthesis inhibition; PRA, plasma renin activity; RBF, renal blood flow; TIVCO, thoracic inferior vena cava obstruction. previously described (15). In 17 dogs, a catheter with an inflatable balloon at its distal end (Fogarty dilation catheter, Edwards Laboratories, Santa Ana, Calif.) was introduced into the inferior vena cava via the femoral vein. The catheter was advanced under fluoroscopy and the balloon was positioned in the thoracic portion of the inferior vena cava. Through the other femoral vein, a catheter was introduced into the lower portion of the abdominal vena cava for recording of the venous pressure (P23Db Statham transducer and Grass polygraph recorder) caudal to the balloon. Through a left flank incision and retroperitoneal dissection, the left renal artery was dissected and fitted with a flow probe of appropriate diameter (Carolina Medical Electronics, Inc., King, N. C.). Renal blood flow was measured with an electromagnetic flowmeter as previously described (17). The left ureter was cannulated with a polyethylene catheter for collection of urine. Through the left ovarian/testicular vein, a small catheter was introduced in retrograde fashion into the left renal vein for blood collection. In all instances aortic and renal vein bloods were obtained simultaneously.

After $1 \mathrm{~h}$ of equilibration, hemodynamic measurements, blood collections and three 10-min clearances were carried out. Subsequently, the balloon placed in the thoracic inferior vena cava was inflated until a slight reduction of the mean arterial blood pressure was observed. 50-60 min later, repeat hemodynamic determinations, blood collections, and three 10-min clearances were performed. To inhibit prostaglandin synthesis, $5 \mathrm{mg} / \mathrm{kg}$ of indomethacin $(n=11)$ prepared as previously described ( 15$)$ or $4 \mathrm{mg} / \mathrm{kg}$ of meclofenamate $(n=6)$ dissolved in $20 \mathrm{ml}$ of $0.9 \%$ saline was administered as a bolus injection. Final hemodynamic measurements, blood collections, and three 10-min clearances were performed 20-30 min later. Because the results for all quantities measured were similar for both prostaglandin inhibitors the data were pooled for statistical evaluation. In five dogs, indomethacin was administered after control hemodynamic measurements without prior obstruction of the inferior vena cava. 20-30 min later the hemodynamic measurements were repeated.

Measurements. The urinary sodium concentration was measured by flame photometry. Glomerular filtration rate was measured by the renal clearance rate of $\left[{ }^{125} \mathrm{I}\right]$ iodothalamate administered as a bolus of $0.9 \mu \mathrm{Ci} / \mathrm{kg}$ dissolved in $10 \mathrm{ml}$ of $0.9 \%$ saline, followed by a sustaining infusion of $0.1 \mu \mathrm{Ci} / \mathrm{kg}$ per $\mathrm{min}$. Blood samples were taken at the midpoint of each renal clearance period. Values expressed are the average of three 10minute clearance periods. Plasma renin activity (PRA) in arterial and renal venous blood was measured as previously described (1.5).

Plasma norepinephrine was measured by the procedure described by Peuler and Johnson (18). Both aortic and renal vein blood $(2 \mathrm{ml})$ were placed in chilled tubes containing EGTA and reduced glutathione $(3.6$ and $2.4 \mathrm{mg}$, respectively) and centrifuged under refrigeration to separate plasma from the cells. Plasma samples $(500 \mu \mathrm{l})$ were mixed with $20 \mu \mathrm{l}$ of $60 \%$ perchloric acid and $50-\mu \mathrm{l}$ aliquots of the deproteinized supernatant fraction were assayed for norepinephrine. Norepinephrine (100 pg) was added to one aliquot from each sample to serve as an internal standard. Blanks, prepared with $0.001 \times \mathrm{NCl}$, were treated in a fashion similar to that of plasma. A reaction mixture was prepared and $100 \mu \mathrm{l}$ of this mixture was pipetted into each sample to begin enzymatic $O$-methylation. The final concentrations of reactants in each sample were as follows: $0.5 \mu \mathrm{M}$, reduced glutathione; $133 \mathrm{mM}, .1 \mathrm{gCl}_{2} 6 \mathrm{H}_{2} \mathrm{O}$; $0.4 \mathrm{M}$, Tris; $18 \mathrm{mM}$, EGTA; $10 \mathrm{mM}$ dithiothreitol; $2.5 \mu \mathrm{Ci}, S$-adenosyl-L-methionine-( $\left[{ }^{3} \mathrm{H}\right]$ methyl $)$ $(9-11 \mathrm{Ci} / \mathrm{mmol})$; and catechol-()-methyl transferase, $0.5 \mathrm{mg}$ of standardized enzyme preparation $(20.5 \mathrm{mg} / \mathrm{ml})(19)$. The $\mathrm{pH}$ of the reaction mixture was 8.9 . At the end of a 60 -min incubation at $38^{\circ} \mathrm{C}$, the reaction was terminated by the addition of $100-\mu \mathrm{l}$ 
aliquots of $1 \mathrm{M}$ sodium borate, $\mathrm{pH} 11.0$, containing $2 \mathrm{mM}$ normetanephrine. The ${ }^{3} \mathrm{H}-\mathrm{O}$-methylated products of the reaction mixture were extracted into $3 \mathrm{ml}$ of toluene-isoamyl alcohol $(3: 2, \mathrm{vol} / \mathrm{vol})$. At this and each extraction step, the aqueous and organic phases were separated by centrifugation. After freezing the aqueous phase in a mixture of dry-iceacetone, the organic phase was decanted into $150 \mu \mathrm{l}$ of $0.1 \mathrm{M}$ acetic acid solution that partitioned the normetanephrine back into the aqueous phase. This phase was washed once with $2.5 \mathrm{ml}$ of toluene-isoamyl alcohol $(3: 2, \mathrm{vol} / \mathrm{vol})$, and the organic layer was aspirated and discarded. Absolute ethanol $(100 \mu \mathrm{l})$ was added to the acetic acid extract and separation of $\left[{ }^{3} \mathrm{H}\right]$ normetanephrine from other $\mathrm{O}$-methylated products was accomplished by thin layer chromatography on 250- $\mu \mathrm{m}$ thickness silica gel plates (Analtech, Inc., Newark, Del.). Plates were developed in tertiary amyl alcohol/toluene/ 40\% methylamine solution (21:7:10). After drying, each plate was scanned under ultraviolet light $(254 \mathrm{~nm})$ to visualize the normetanephrine, and the corresponding zone was scraped into a scintillation vial. To each scintillation vial was added in succession the following solutions: $1 \mathrm{ml}$ of $50 \mathrm{mM}$ ammonium hydroxide solution to elute the methylated derivative from the silica gel, $50 \mu \mathrm{l}$ of $4 \%$ sodium periodate to convert $\left[{ }^{3} \mathrm{H}\right]$ normetanephrine to $\left[{ }^{3} \mathrm{H}\right]$ vanillin and, after $5 \mathrm{~min}, 50 \mu \mathrm{l}$ of glycerol $(10 \% \mathrm{vol} / \mathrm{vol})$ to eliminate unreacted periodate. The resulting solution was then acidified with $1 \mathrm{ml}$ of $0.1 \mathrm{~N}$ acetic acid and the $\left[{ }^{3} \mathrm{H}\right]$ vanillin was partitioned into $10 \mathrm{ml}$ of toluene/ Liquifluor (20:1) with vigorous mixing. Radioactivity in these samples was determined by counting in a Packard Tri-carb Scintillation Spectrometer, model 3330 (Packard Instrument Co., Inc., Downers Grove, Ill.). The accuracy of the assay was assessed by the recovery of standard amounts $(25-755 \mathrm{pg})$ of norepinephrine added to a dog plasma pool. Linear regression analysis of the recovered standard gave $y=1.04 x-1.3$ $(r=0.998 ; n=14)$ where $y$ is the amount of standard recovered (corrected for endogenous concentration) and $x$ is the amount of norepinephrine added. Reproducibility of the assay was determined by the measurement of aliquots of the same plasma pool. When aliquots were measured in eight different runs, the mean $\pm S D$ concentration was $440 \pm 20$ $\mathrm{pg} / \mathrm{ml}$. The interassay coefficient of variation was $5 \%$.

$\mathrm{PGE}_{2}$ was measured by radioimmunoassay. $\left[{ }^{3} \mathrm{H}\right] \mathrm{PGE}_{2}$ was obtained from Amersham Corp. (Arlington Heights, Ill.) (160 $\mathrm{Ci} / \mathrm{mmol}$ ) and $\mathrm{PGE}_{2}$ antisera was obtained from Boehringer Mannheim Biochemicals (Indianapolis, Ind.). The percentage of crossreactivity of various prostaglandins and the antibody is $<0.3 \%$ for PG $A_{1}, A_{2}, B_{1}, B_{2}, F_{2 \alpha}$ and $<3.4 \%$ for PGE $_{1}$ and 6keto- $F_{1 \alpha}(20)$. Blood was collected in heparinized, chilled tubes containing $10 \mu \mathrm{g}$ indomethacin $/ \mathrm{ml}$ in blood. After separation, the plasma was stored at $-20^{\circ} \mathrm{C}$ until assay time. To $2 \mathrm{ml}$ of plasma, $\sim 1,000 \mathrm{cpm}$ of $\left[{ }^{3} \mathrm{H}\right] \mathrm{PGE}_{2}$ were added for recovery estimation. The samples were then acidified to $\mathrm{pH}$ 3.5 with formic acid and extracted with $5 \mathrm{ml}$ of ethylacetate. The organic layer was then collected and dried under $\mathrm{N}_{2}$. The dried extracted samples were redissolved in $0.5 \mathrm{ml}$ of $0.1 \mathrm{M}$ phosphate buffer (pH 7.40) containing $0.1 \mathrm{mg} / \mathrm{ml} \mathrm{Brij} 35$ to facilitate $\mathrm{PGE}_{2}$ recovery. The mean $\pm \mathrm{SD}$ overall recovery of $\left[{ }^{3} \mathrm{H}\right] \mathrm{PGE}_{2}$ from plasma after extraction was $95 \pm 7 \%(n=19)$. After taking aliquots for recovery estimation, 100- $\mu$ l aliquots of sample were added to assay tubes containing $\sim 8,000 \mathrm{cpm}$ of $\left[{ }^{3} \mathrm{H}\right] \mathrm{PGE}_{2}$ (equivalent to $12 \mathrm{pg}$ ), dissolved in $100 \mu \mathrm{l}$ of redistilled water, and $100 \mu \mathrm{l}$ of diluted antisera in phosphate buffer. Standards containing 3-708 pg of unlabeled $\mathrm{PGE}_{2}$ were treated in a similar manner. After incubation for $10 \mathrm{~min}$ at room temperature followed by $2 \mathrm{~h}$ at $4^{\circ} \mathrm{C}$, the bound and free $\mathrm{PGE}_{2}$ were separated by a charcoal-dextran mixture. The final antisera dilution resulted in an initial binding of $\sim 40 \%$. Nonspecific binding was $2.1 \pm 1.2 \%$ (mean $\pm S D ; n=10$ ). Standard curves were analyzed by the method of Rodbard and
Hutt (21) which is a nonlinear transformation of the logitlog relationship. A $10 \%$ decrease in bound counts was observed at $3.4 \pm 0.1 \mathrm{pg}$ (mean $\pm \mathrm{SD} ; n=5$ ). The mean $\pm \mathrm{SD}$ amount of $\mathrm{PGE}_{2}$ required to displace zero point binding by $50 \%$ was $28 \pm 12$ pg $(n=10)$. Extraction blanks averaged $<2$ pg. The accuracy of the assay was assessed by the recovery of standard amounts of PGE $_{2}$ (9.4-944 pg) added to a plasma pool. Linear regression analysis of the recovery standards gave: $y=0.94 x$ $+18(r=0.96 ; n=28)$, where $y$ is the amount of standard recovered and $x$ is the amount of $\mathrm{PGE}_{2}$ added. The reproducibility of the assay was determined by measurements of aliquots of the same plasma pool. When eight aliquots were measured in the same assay run, the mean $\pm S D$ concentration was $81 \pm 11 \mathrm{pg} / \mathrm{ml}$; the intraassay coefficient of variation was $13 \%$. When aliquots of three separate plasma pools were measured in different assay runs, the mean \pm SD concentrations were: $15 \pm 3 \mathrm{pg} / \mathrm{ml}(n=8) ; 43 \pm 8 \mathrm{pg} / \mathrm{ml}(n=7) ; 95 \pm 20$ $\mathrm{pg} / \mathrm{ml}(n=7)$. The interassay coefficients of variation were 20 , 19 , and $21 \%$, respectively.

Statistical analysis. All values are expressed as mean \pm SEM. Data were analyzed by analysis of variance or a paired $t$ test (22). Differences were termed significant if the $F$ or $t$ value exceeded the $5 \%$ level.

\section{RESULTS}

Table I depicts the effects of partial obstruction of the thoracic inferior vena cava and subsequent inhibition of prostaglandin synthesis upon systemic and renal hemodynamics. Inflation of the balloon in the thoracic inferior vena cava increased the venous pressure caudal to the balloon from 2.9 to $12.5 \mathrm{~mm} \mathrm{Hg}(P<0.01)$. This resulted in a fall in the mean cardiac output from 3.69 to 2.15 liters $/ \mathrm{min}(P<0.01)$, a decrease in arterial blood pressure from 132 to $111 \mathrm{mg} \mathrm{Hg}(P<0.01)$ and an increase in total peripheral vascular resistance from 37.6 to 57.9 arbitrary resistance units $(\mathrm{RU})(P<0.01)$. The response of the renal circulation to inflation of the balloon contrasted markedly with these changes; the average renal blood flow decreased slightly but not significantly from 224 to $203 \mathrm{ml} / \mathrm{min}$ and the mean renal vascular resistance remained unchanged (0.66 vs. 0.61 arbitrary resistance units [ru]). There was a small but significant increase in arterial hematocrit after inflation of the balloon ( 35 vs. $37 \% ; P<0.05$ ).

Administration of inhibitors of prostaglandin synthesis had no significant effect upon the inferior vena cava and arterial pressures, cardiac output or total peripheral vascular resistance (Table 1). In marked contrast, however, renal blood flow fell from 203 to $156 \mathrm{ml} / \mathrm{min}(P<0.01)$ and the renal vascular resistance increased from 0.61 to $1.05 \mathrm{ru}(P<0.05)$ after administration of the prostaglandin synthesis inhibitors. In the group of five dogs that received indomethacin without prior lowering of the cardiac output, there were no significant changes in the average mean arterial blood pressure $(130 \pm 2$ to $127 \pm 2 \mathrm{~mm} \mathrm{Hg})$, cardiac output (4.32 \pm 0.40 to $4.10 \pm 0.59$ liters $/ \mathrm{min})$, or renal blood flow $(243 \pm 23$ to $240 \pm 42 \mathrm{ml} / \mathrm{min})$.

Table II depicts the changes in the renal plasma 
TABLE I

Effect of Obstruction of the Thoracic Inferior Vena Cava and Subsequent Inhibition of the Prostaglandin Synthesis on Systemic and Renal Hemodynamics

\begin{tabular}{lccccccc}
\hline & IVCP & MAP & CO & TPVR & RBF & RVR & Hct \\
\hline \multicolumn{2}{c}{$m m$ Hg } & & liters $/ \min$ & $R U$ & $m l / m i n$ & $r u$ & $\%$ \\
Control & $2.9 \pm 0.5$ & $132 \pm 4$ & $3.69 \pm 0.90$ & $37.6 \pm 2.5$ & $224 \pm 16$ & $0.66 \pm 0.06$ & $35 \pm 1$ \\
TIVCO & $12.5 \pm 1.0$ & $111 \pm 5$ & $2.15 \pm 0.19$ & $57.9 \pm 4.8$ & $203 \pm 19$ & $0.61 \pm 0.05$ & $37 \pm 1$ \\
PGSI & $11.2 \pm 0.9$ & $107 \pm 6$ & $2.36 \pm 0.24$ & $52.4 \pm 5.1$ & $156 \pm 21$ & $1.05 \pm 0.21$ & $38 \pm 2$ \\
$P(2$ vs. 1) & $<0.01$ & $<0.01$ & $<0.01$ & $<0.01$ & NS & NS & $<0.05$ \\
$P(3$ vs. 2) & NS & NS & NS & NS & $<0.01$ & $<0.05$ & NS \\
\hline
\end{tabular}

$n=17$. All values are mean \pm SEM. IVCP, inferior vena cava pressure; MAP, mean arterial pressure; CO, cardiac output; TPVR, total peripheral vascular resistance in arbitrary resistance units (RU); RVR, renal vascular resistance in arbitrary resistance units (ru); Hct, hematocrit.

flow, glomerular filtration rate, urine flow, and urinary sodium excretion. Although the arterial hematocrit was significantly higher (Table I), the average renal plasma flow, like renal blood flow, was not significantly lower than control during obstruction of the thoracic inferior vena cava (Table II). The glomerular filtration rate fell significantly from $49 \pm 3$ to $36 \pm 9 \mathrm{ml} / \mathrm{min}$ in response to caval obstruction $(P<0.01)$; the slight reduction in filtration fraction was not statistically significant. Urine flow rate, urinary sodium excretion and the fractional excretion of sodium fell significantly in response to acute heart failure. Inhibition of prostaglandin synthesis during obstruction of the thoracic inferior vena cava reduced renal plasma flow from 126 to $96 \mathrm{ml} / \mathrm{min}$ $(P<0.01)$ but produced no significant changes in glomerular filtration rate, filtration fraction, urinary flow rate, urinary sodium excretion rate, or fractional sodium excretion.

Table III depicts the values of PRA in arterial and renal venous blood. During the control period, PRA in the renal vein blood $(2.5 \mathrm{ng} / \mathrm{ml}$ per $\mathrm{h}$ ) was slightly but significantly higher than arterial PRA (1.8 ng/ml per $h$ ); the renal secretion rate of renin averaged 95 $\mathrm{U} / \mathrm{min}$. Inflation of the balloon in the thoracic inferior vena cava resulted in significant increases in the PRA in arterial and renal venous blood; the rate of renal renin secretion increased from 95 to $1,795 \mathrm{U} / \mathrm{min}$ $(P<0.01)$. The subsequent administration of the inhibitors of prostaglandin synthesis had no significant effect upon the PRA in arterial or renal venous blood or the rate of renin secretion by the kidney.

Table IV shows the plasma concentrations of norepinephrine in arterial and renal venous blood. Under control conditions, the concentration of norepinephrine in the renal venous plasma was significantly greater than that of arterial plasma (204 vs. $106 \mathrm{pg} / \mathrm{ml}$; $P<0.01$ ); the calculated net rate of norepinephrine overflow ${ }^{2}$ during control averaged $13,280 \mathrm{pg} / \mathrm{min}$. After

\footnotetext{
${ }^{2}$ Since norepinephrine is both metabolized and secreted by the mammalian kidney (23), the calculated net rate of norepinephrine overflow would be expected to underestimate that fraction of neurotransmitter which is released in the kidney and escapes into the circulation. The quantities of norepinephrine metabolized and secreted in a single passage through the renal circulation is unknown; the term net rate of norepinephrine overflow as used in this paper carries no implications about the exact influence of arterial norepinephrine concentration upon renal venous norepinephrine concentration.
}

TABLE II

Effect of Obstruction of the Thoracic Inferior Vena Cava and Subsequent Inhibition of the Prostaglandin Synthesis on Renal Function

\begin{tabular}{lcccccc}
\hline & RPF & GFR & FF & V & $\mathrm{U}_{\mathrm{Na}^{+} \cdot \mathrm{V}}$ & FE $_{\mathrm{Na}^{+}}$ \\
\hline \multicolumn{2}{c}{$m l / m i n$} & & $m l / m i n$ & $\mu e q / m i n$ & $\%$ \\
Control & $142 \pm 9$ & $49 \pm 3$ & $0.35 \pm 0.01$ & $1.22 \pm 0.17$ & $215 \pm 29$ & $3.3 \pm 0.4$ \\
TIVCO & $126 \pm 11$ & $36 \pm 9$ & $0.29 \pm 0.04$ & $0.21 \pm 0.05$ & $30 \pm 7$ & $0.6 \pm 0.2$ \\
PGSI & $96 \pm 12$ & $31 \pm 8$ & $0.35 \pm 0.05$ & $0.20 \pm 0.06$ & $23 \pm 6$ & $0.4 \pm 0.1$ \\
$P(2$ vs. 1) & NS & $<0.01$ & NS & $<0.01$ & $<0.01$ & $<0.01$ \\
$P(3$ vs. 2) & $<0.01$ & NS & NS & NS & NS & NS \\
\hline
\end{tabular}

$n=17$. Values are mean \pm SEM. RPF, renal plasma flow; GFR, glomerular filtration rate; FF, filtration fraction; $\mathrm{V}$, urine flow rate; $\mathrm{U}_{\mathrm{Na}^{+}}+\mathrm{V}$, urinary excretion rate of sodium; $\mathrm{FE}_{\mathrm{Na}^{+}}$, fractional excretion of filtered sodium. 
TABLE III

Effect of Obstruction on the Thoracic Inferior Vena Cava and Subsequent Inhibition of the Prostaglandin Synthesis on Plasma Renin Activity in Arterial and Renal Venous Bloods and its Renal Secretion Rate

\begin{tabular}{lccccc}
\hline & $\mathrm{A}$ & $\mathrm{RV}$ & $\Delta \pm$ SEM & $P$ & RSR \\
\hline \multicolumn{5}{c}{$n g / m l$ per $h$} \\
Control & $1.8 \pm 0.3$ & $2.5 \pm 0.5$ & $0.7 \pm 0.2$ & $<0.01$ & U/min \\
TIVCO & $25.9 \pm 4.6$ & $39.8 \pm 6.7$ & $13.9 \pm 2.7$ & $<0.01$ & $1,795 \pm 29$ \\
PGSI & $27.3 \pm 5.0$ & $45.0 \pm 9.4$ & $17.7 \pm 5.6$ & $<0.01$ & $1,099 \pm 286$ \\
$P$ (2 vs. 1) & $<0.01$ & $<0.01$ & & & $<0.01$ \\
$P$ (3 vs. 2) & NS & NS & & & NS \\
\hline
\end{tabular}

$n=16$. Values are mean \pm SEM. A, arterial; RV, renal vein; RSR, renal secretion rate $=(\mathrm{RV}-\mathrm{A}) \cdot[\mathrm{RBF} \cdot(\mathrm{l}-\mathrm{Hct})]$ in arbitrary units.

partial obstruction of the thoracic inferior vena cava, the norepinephrine concentration in the arterial plasma increased significantly from 106 to $316 \mathrm{pg} / \mathrm{ml}(P<0.05)$; the renal venous norepinephrine concentration also increased from 204 to $496 \mathrm{pg} / \mathrm{ml}(P<0.01)$. Despite the fact that the average renal venous-arterial concentration difference rose during caval balloon inflation from 98 to $180 \mathrm{pg} / \mathrm{ml}$, the increase in the net rate of renal norepinephrine overflow (from 13,280 to 67,971 $\mathrm{pg} / \mathrm{min}$ ) was not statistically significant. Following administration of the inhibitors of prostaglandin synthesis, there was no significant change in the norepinephrine concentration in arterial plasma, but there was a significant increase in the norepinephrine concentration in the renal venous plasma. This may have been due to the marked fall in renal blood flow (Table I), since the renal venous-arterial norepinephrine concentration difference and the net rate of norepinephrine overflow from the kidney were unchanged after administration of the inhibitors of prostaglandin synthesis (Table IV).

Table V shows the concentration of $\mathrm{PGE}_{2}$ in arterial and renal venous plasma during obstruction of the thoracic inferior vena cava and during subsequent ad- ministration of the inhibitors of prostaglandin synthesis. The control renal venous concentration of $\mathrm{PGE}_{2}$ was not statistically different from the arterial $\mathrm{PGE}_{2}$ concentration. The calculated net rate of renal $\mathrm{PGE}_{2}$ secretion $^{3}$ during the control period averaged $1,614 \mathrm{pg} / \mathrm{min}$, a value not significantly different from zero. In response to obstruction of the thoracic inferior vena cava there was no significant change in arterial $\mathrm{PGE}_{2}$; however, the renal venous plasma $\mathrm{PGE}_{2}$ concentration increased markedly from 34 to $129 \mathrm{pg} / \mathrm{ml}(P<0.01)$. Consequently, the net rate of renal $\mathrm{PGE}_{2}$ secretion rose from 1,614 to $11,743 \mathrm{pg} / \mathrm{min}(P<0.01)$. The subsequent administration of indomethacin or meclofenamate did not change arterial $\mathrm{PGE}_{2}$, but greatly reduced the mean renal venous $\mathrm{PGE}_{2}$ concentration from 129 to $19 \mathrm{pg} / \mathrm{ml}(P<0.01)$; the calculated net renal secretion of $\mathrm{PGE}_{2}$ was not different from zero after blockade of the prostaglandin synthesis.

\footnotetext{
${ }^{3}$ Because the kidney is rich in prostaglandin degradating enzymes (24), similar uncertainties exist about the exact fate of arterial $\mathrm{PGE}_{2}$ entering the kidney, as in the case of norepinephrine. Thus, the exact influence of arterial $\mathrm{PGE}_{2}$ concentration upon renal venous $\mathrm{PGE}_{2}$ concentration is unknown.
}

TABLE IV

Effect of Obstruction of the Thoracic Inferior Vena Cava and Subsequent Inhibition of the Prostaglandin Synthesis on Plasma Concentrations of Norepinephrine in Arterial and Renal Venous Bloods and its Renal Secretion Rate

\begin{tabular}{lccccc}
\hline & A & RV & $\Delta \pm$ SEM & $P$ & Net overflow \\
\hline \multicolumn{1}{c}{$p g / m l$} \\
Control & $106 \pm 13$ & $204 \pm 36$ & $98 \pm 27$ & $<0.01$ & $13,280 \pm 3,834$ \\
TIVCO & $316 \pm 44$ & $496 \pm 62$ & $180 \pm 40$ & $<0.01$ & $67,971 \pm 43,787$ \\
PGSI & $489 \pm 131$ & $674 \pm 97$ & $185 \pm 75$ & $<0.05$ & $19,739 \pm 4,438$ \\
$P(2$ vs. 1) & $<0.05$ & $<0.01$ & & & NS \\
$P(3$ vs. 2$)$ & NS & $<0.05$ & & & NS \\
\hline
\end{tabular}

$n=16$. Values are mean \pm SEM. Net overflow $=(\mathrm{V}-\mathrm{A}) \cdot[\mathrm{RBF} \cdot(1-\mathrm{Hct})]$. See Table III for abbreviations. 
TABLE V

Effect of Obstruction of the Thoracic Inferior Vena Cava and Subsequent Inhibition of the Prostaglandin Synthesis on Plasma Concentration of $P G E_{2}$ in Arterial and Renal Venous Bloods and its Renal Secretion Rate

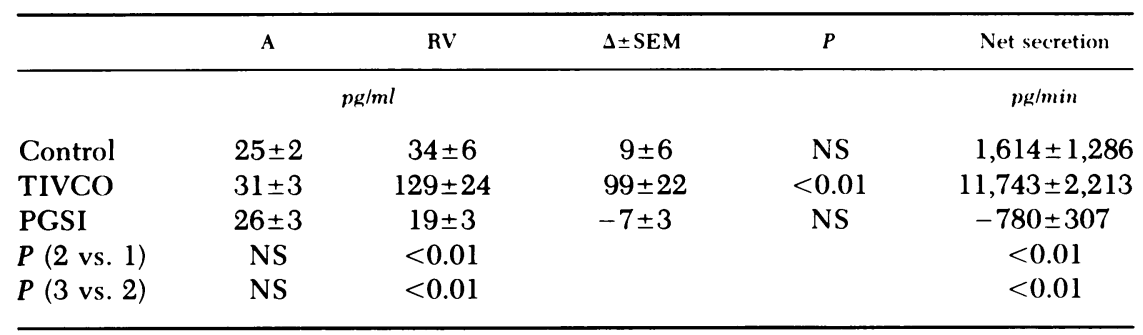

$n=16$. Values are mean \pm SEM. Net secretion $=(\mathrm{V}-\mathrm{A}) \cdot[\mathrm{RBF} \cdot(\mathrm{l}-\mathrm{Hct})]$. See Table III for abbreviations.

\section{DISCUSSION}

In the present study, the lowering of venous return to the heart by inflation of a balloon placed in the thoracic inferior vena cava decreased the cardiac output markedly $(-42 \pm 4 \% ; P<0.01)$ and lowered the mean arterial pressure $(-16 \pm 3 \% ; P<0.01)$. (Fig. 1). The increase in the total peripheral vascular resistance $(57 \pm 9 \% ; P<0.01)$ that accompanied these changes, did not include the renal circulation; after inflation of the balloon the renal blood flow fell only slightly and insignificantly from 224 to $203 \mathrm{ml} / \mathrm{min}(-8 \pm 7 \%)$ and the renal vascular resistance remained unchanged $(-3 \pm 6 \%)$. These results, with respect to the renal circulation during an acute lowering of the cardiac output, are in agreement with data obtained by others in anesthetized dogs with acute partial constriction of the pulmonary artery $(3,4)$; and in unanesthetized dogs with ventricular bradycardia (5), or with partial occlusion of the thoracic inferior vena cava (6).

The absence of renal vasoconstriction during the acute reduction of cardiac output is noteworthy because arterial plasma renin activity and arterial plasma concentration of norepinephrine were markedly elevated in response to thoracic caval obstruction (Tables III and IV) and because angiotensin II and norepinephrine are both renal vasoconstrictors (15). During acute heart failure, the renal venous renin activity and renal venous plasma norepinephrine concentration increased above control values. Since we have previously shown that changes in renal venous norepinephrine concentration reflect changes in the frequency of renal nerve discharges (25), the observation of enhanced renal venous norepinephrine concentration during obstruction of the vena cava demonstrates, for the first time, that the augmented sympathetic tone in acute heart failure includes the renal sympathetic nerves.

Two findings from the present study strongly suggest that enhanced renal prostaglandin synthesis was responsible for the lack of renal vasoconstriction observed during the acute fall in the cardiac output. First, inflation of the balloon in the vena cava resulted in a marked increase in the renal venous plasma concentration of $\mathrm{PGE}_{2}$ and the corresponding net rate of renal secretion (Table V); the administration of indometha-

MAP

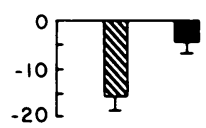

CO

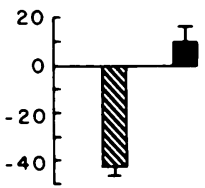

RBF

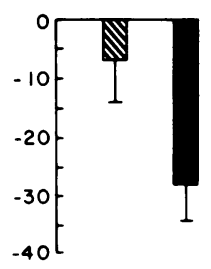

TPVR

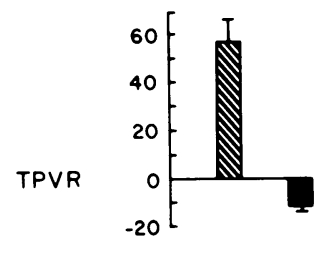

RVR

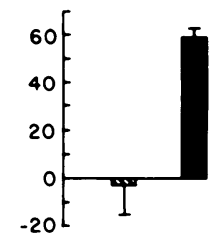

WV

TIVCO vs. CONTROL, \%

PGSI vs. TIVCO, \%

FIGURE 1 Systemic and renal hemodynamic changes induced by obstruction of the thoracic inferior vena cava and subsequent prostaglandin synthesis inhibition. Vertical lines indicate mean \pm SEM. $n=17$. MAP, mean arterial pressure; $\mathrm{CO}$, cardiac output; TPVR, total peripheral vascular resistance; RVR, renal vascular resistance. 
cin or meclofenamate markedly lowered the concentration of $\mathrm{PGE}_{2}$ in renal venous plasma, and the net secretion of this prostaglandin by the kidney. Since the release of prostaglandins reflects de novo biosynthesis (26), these results indicate that renal $\mathrm{PGE}_{2}$ synthesis was enhanced during acute lowering of the cardiac output and that effective inhibition of renal prostaglandin synthesis was accomplished with indomethacin or meclofenamate. Second, as shown in Fig. 1, during inflation of the thoracic caval balloon, total peripheral vascular resistance was greatly increased $(57 \pm 9 \%$; $P<0.01$ ), but renal vascular resistance was unchanged from control; the subsequent administration of inhibitors of prostaglandin synthesis had no effect on the total peripheral vascular resistance, but markedly reduced renal blood flow, and increased the renal vascular resistance. Administration of indomethacin to animals without thoracic caval obstruction, on the other hand, had no effect on the renal blood flow.

In the aggregate, these data suggest that the renal prostaglandins were counteracting the vasoconstrictor mechanisms activated during acute heart failure and that after inhibition of renal prostaglandin synthesis the effect of the vasoconstrictor mechanisms acting elsewhere in the systemic circulation were also expressed in the renal circulation. Support for this interpretation derives from pharmacological studies indicating that prostaglandin inhibition potentiates the renal vasoconstrictor effects of exogenous angiotensin II $(27,28)$, of norepinephrine (27), and of renal nerve stimulation $(14,29)$.

The data from the present study are also consonant with results obtained in other conditions in which there has been activation of the renin-angiotensin system. Renal prostaglandin synthesis is increased in sodium depletion (30), hemorrhagic hypotension (31), renal artery constriction (31), and cirrhosis with ascitis (33). In all these conditions, administration of inhibitors of prostaglandin synthesis reduces renal blood flow (12, $15,16,31)$. The mechanism(s) whereby the prostaglandins attenuate renal vasoconstrictor mechanisms remains to be determined. We have recently shown that the renal norepinephrine overflow is unchanged by inhibition of prostaglandin synthesis (34), suggesting that the site of action where prostaglandins oppose the vascular effect of the sympathetic nerves is distal to the axon terminals. Since prostaglandins have intrinsic renal vasodilator action (17), it is likely that they attenuate the renal vascular effects of norepinephrine and angiotensin II by directly acting upon the vascular smooth muscle cells.

The cellular origin of the $\mathrm{PGE}_{2}$ in the renal venous plasma and the stimuli responsible for the increase in the $\mathrm{PGE}_{2}$ concentration during decreased cardiac output remain to be defined. Biosynthesis of $\mathrm{PGE}_{2}$ has been demonstrated in vascular endothelial and smooth muscle cells $(35,36)$, as well as renal interstitial cells (37). It appears reasonable to postulate that the increased overflow of $\mathrm{PGE}_{2}$ into renal venous blood observed during the decrease of the cardiac output results, at least in part, from enhanced synthesis of $\mathrm{PGE}_{2}$ in the renal vasculature. The most likely stimuli responsible for this enhancement are the elevated levels of angiotensin II (renin) and norepinephrine. Angiotensin II stimulates $\mathrm{PGE}_{2}$ synthesis in in vitro conditions in endothelial (35) vascular smooth muscle (36) and renal interstitial (37) cells, and intrarenal infusions of angiotensin II cause increased biosynthesis of $\mathrm{PGE}_{2}$ in the kidney (32). Similarly, intrarenal infusions of norepinephrine and renal nerve stimulation (38) enhance the release of PGE-like substances from the kidney and norepinephrine stimulates prostaglandin synthesis in isolated canine kidney cells (39).

Although the glomerular filtration rate often does not change or decreases less than the renal plasma flow during acute heart failure (2), in the present study, the glomerular filtration rate fell considerably more than the renal plasma flow. This somewhat suprising finding has previously been reported in studies in which heart failure was induced in animals that received a moderate sodium load $(4,40)$. Since the pressures and flows which determine the rate of glomerular filtration (41) were not measured in the present study, the mechanism responsible for the reduction of the glomerular filtration despite an unchanged renal plasma flow remains to be elucidated.

Despite the significant decrease in the renal plasma flow induced by inhibition of the prostaglandin synthesis in the dogs with acute heart failure, golmerular filtration did not change. This finding is in agreement with other studies in which inhibition of prostaglandins reduced renal blood flow but had no effect on glomerular filtration rate (28); however, it contrasts with the observations that prostaglandin blockade significantly reduced the glomerular filtration rate in dogs with hypotensive hemorrhage $(14,31)$ and in patients with Bartter's syndrome (42), with the nephrotic syndrome (43), and with cirrhosis with ascitis (16).

In summary, the present study demonstrates that the acute lowering of cardiac output increased peripheral vascular resistance and arterial PRA and norepinephrine concentration. Renal venous PRA and plasma concentrations of norepinephrine and $\mathrm{PGE}_{2}$ were also augmented during acute heart failure. Despite the systemic vasoconstriction, renal vascular resistance was unaffected by decreasing the cardiac output. Administration of inhibitors of prostaglandin synthesis decreased $\mathrm{PGE}_{2}$ concentration in renal vein plasma and markedly reduced renal blood flow and increased renal vascular resistance, but had no significant effect upon total peripheral vascular resistance. The data suggest that the renal blood flow is maintained during acute 
heart failure by the effect(s) of the enhanced renal prostaglandin synthesis to oppose the vasoconstrictor mechanisms acting elsewhere in the circulation.

\section{ACKNOWLEDGMENTS}

Expert technical assistance was provided by Ms. Deborah L. Brennan, Mr. Gilbert LeCren, and Mr. Jeffrey Zessinger. Ms. Kathleen Mulrenin provided excellent and patient secretarial assistance. Indomethacin was a gift of Merck Sharpe \& Dohme Research Laboratory, West Point, Pa. Meclofenamate was generously provided by Warner-Lambert Co. Pharmaceutical Research Division, Ann Arbor, Mich.

This work was supported by grant HL 10182 from the National Heart, Lung and Blood Institute.

\section{REFERENCES}

1. Merrill, A. J. 1946. Edema and decreased renal blood flow in patients with congestive heart failure. Evidence of "forward failure" as the primary cause of edema. J. Clin. Invest. 25: 389-400.

2. Auld, R. B., E. A. Alexander, and N. G. Levinsky. 1971. Proximal tubular function in dogs with thoracic caval constriction. J. Clin. Invest. 50: 2150-2158.

3. Berne, R. M., and M. N. Levy. 1950. Effects of acute reduction of cardiac output on the renal circulation of the dog. J. Clin. Invest. 29: 444-454.

4. Levy, M. N., and R. M. Berne. 1951. Effects of acute reduction of cardiac output upon the mechanisms of sodium excretion in the dog. Am. J. Physiol. 166: 262-268.

5. White, S., T. Patrick, C. B. Higgins, S. F. Vatner, D. Franklin, and E. Braunwald. 1971. Effects of altering ventricular rate on blood flow distribution in conscious dogs. Am. J. Physiol. 221: 1402-1407.

6. Higgins, C. B., S. F. Vatner, D. Franklin, and E. Braunwald. 1974. Pattern of differential vasoconstriction in response to acute and chronic low-output states in the conscious dog. Cardiovasc. Res. 8: 92-98.

7. Watkins, L., Jr., J. A. Burton, E. Haber, J. R. Cart, F. W. Smith, and A. C. Barger. 1976. The renin-angiotensinaldosterone system in congestive failure in conscious dogs. J. Clin. Invest. 57: 1606-1617.

8. Curtiss, C., J. N. Cohn, T. Brobel, and J. A. Franciosa. 1978. Role of the renin-angiotensin system in the systemic vasoconstriction of chronic congestive heart failure. Circulation. 58: 763-770.

9. Chidsey, C. A., D. Harrison, and E. Braunwald. 1962. Augmentation of the plasma norepinephrine response to exercise in patients with congestive heart failure. N. Eng. J. Med. 267: 650-654.

10. Zins, G. R. 1975. Renal prostaglandins. Am. J. Med. 58: $14-24$.

11. Swain, J.A., G. R. Heydrincks, D. H. Boettcher, and S. F. Vatner. 1975. Prostaglandin control of renal circulation in the unanesthetized dog and baboon. Am. J. Physiol. 229: 826-830.

12. Satoh, S., and B. G. Zimmerman. 1975. Influence of the renin-angiotensin system on the effect of prostaglandin synthesis inhibitors in the renal vasculature. Circ. Res. 36, 37(Suppl. I):I-89-I-96.

13. Vatner, S. F. 1974. Effects of hemorrhage on regional blood flow distribution in dogs and primates. J. Clin. Invest. 54: 225-235.

14. Henrich, W. L., T. Berl, K. M. McDonald, R. J. Anderson, and R. W. Schrier. 1978. Angiotensin II, renal nerves, and prostaglandins in renal hemodynamics during hemorrhage. Am. J. Physiol. 235: F46-F51.

15. Oliver, J. A., and P. J. Cannon. 1978. The effect of altered sodium balance upon renal vascular reactivity to angiotensin II and norepinephrine in the dog. Mechanism of variation in angiotensin responses. J. Clin. Invest. 61: 610-623.

16. Boyer, T. D., P. Zia, and T. B. Reynolds. 1979. Effect of indomethacin and prostaglandin $A_{1}$ on renal function and plasma renin activity in alcoholic liver disease. Gastroenterology. 77: 215-222.

17. Oliver, J. A., R. R. Sciacca, and P. J. Cannon. 1979. Renal vascular and excretory responses to prostaglandin endoperoxides in the dog. Am. J. Physiol. 236:(3): H427-H433.

18. Peuler, J. D., and G. Johnson. 1977. Simultaneous single isotope radioenzymatic assay of plasma norepinephrine, epinephrine and dopamine. Life Sci. 625-636.

19. Ben-Jonathan, N., and J. C. Porter. 1976. A sensitive radioenzymatic assay for dopamine, norepinephrine and epinephrine in plasma and tissue. Endocrinology. 98: 1497-1507.

20. Gunther, S., and P. J. Cannon. 1980. Modulation of angiotensin II coronary vasoconstriction by cardiac prostaglandin synthesis. Am. J. Physiol. 238: H895-H901.

21. Rodbard, D., and D. M. Hutt. 1974. Statistical analysis of radioimmunoassay and immunoradiometric (labeled antibody) assay In: Radioimmunoassays and Related Procedures in Medicine. International Atomic Energy Agency, Vienna. 1: 165-189.

22. Winer, B. J. 1971. Statistical Principles in Experimental Design. McGraw-Hill Inc. New York, 2nd edition. pp. 4-36; 261-308; 752-812.

23. Silva, P., L. Landsberg, and A. Besarab. 1979. Excretion and metabolism of catecholamines by the isolated perfused rat kidney. J. Clin. Invest. 64: 850-857.

24. Anggard, E., C. Larsson, and B. Samuelsson. 1971. The distribution of 15-hydroxy prostaglandin dehydrogenase and prostaglandin- $\Delta^{13}$-reductase in tissues of the swine. Acta Physiol. Scand. 81: 396-404.

25. Oliver, J. A., J. Pinto, R. R. Sciacca, and P. J. Cannon. 1980. Basal norepinephrine overflow into the renal vein; effect of renal nerve stimulation. Am. J. Physiol. 239: F371-F377.

26. Piper, P., and J. Vane. 1971. The release of prostaglandins from lung and other tissues. Ann. New York Acad. Sci. 18: $363-385$.

27. Aiken, J. W., and J. R. Vane. 1973. Intrarenal prostaglandin release attenuates the renal vasoconstrictor activity of angiotensin. J. Pharmacol. Exp. Ther. 184: 678-687.

28. Baylis, C., and B. M. Brenner. 1978. Modulation by prostaglandin synthesis inhibitors of the action of exogenous angiotensin II on glomerular ultrafiltration in the rat. Circ. Res. 43: 889-898.

29. Malik, K. U., and J.C. McGiff. 1975. Modulation by prostaglandins of adrenergic transmission in the isolated perfused rabbit and rat kidney. Circ. Res. 36: 599-609.

30. Stahl, R. A. K., A. A. Attallah, D. L. Bloch, and J. B. Lee. 1979. Stimulation of rabbit renal $\mathrm{PGE}_{2}$ biosynthesis by dietary sodium restriction. Am. J. Physiol. 237: F344-F349.

31. Henrich, W. L., R. L. Anderson, A. S. Berns, K. M. McDonald, P. J. Paulsen, and T. Berl. 1978. The role of renal nerves and prostaglandins in control of renal hemodyamics and plasma renin activity during hypotensive hemorrhage in the dog. J. Clin. Invest. 61: 744-750.

32. Dunn, M. J., J. F. Liard, and F. Dray. 1978. Basal and stimulated rates of renal secretion and excretion of pros- 
taglandins $E_{2}, F_{\alpha 1}$, and 13, 14-dihydro-15 keto $F_{\alpha}$ in the dog. Kidney Int. 13: 136-143.

33. Zia, P., R. Zipser, P. Speckart, and R. Horton. 1978. The measurement of urinary prostaglandin $\mathrm{E}$ in normal subjects, and in high-renin states. J. Lab. Clin. Med. 92: 415-411.

34. Oliver, J. A., J. Pinto, R. R. Sciacca, and P. J. Cannon. 1980. The role of prostaglandins in the regulation of norepinephrine release. Clin. Res. 28: 535A. (Abstr.)

35. Gimbrone, M. A., Jr., and R. W. Alexander. 1975. Angiotensin II stimulation of prostaglandin production in cultured human vascular endothelium. Science (Wash. D. C.). 189: 219-220.

36. Alexander, R. W., and M. A. Gimbrone. 1976. Stimulation of prostaglandin $\mathrm{E}$ synthesis in cultured human umbilical vein smooth muscle cells. Proc. Natl. Acad. Sci. U. S. A. 73: $1617-1620$.

37. Zusman, R. M., and H. R. Keiser. 1977. Prostaglandin biosynthesis by rabbit renomedullary interstital cells in tissue culture. Stimulation by angiotensin II, bradykinin, and arginine vasopressin. J. Clin. Invest. 60: 215-223.
38. Dunham, E. W., and B. G. Zimmerman. 1970. Release of prostaglandin-like material from dog kidney during nerve stimulation. Am. J. Physiol. 219: 1279-1285.

39. Levine, L., and M. A. Moskowitz. 1979. $\alpha$-and $\beta$-adrenergic stimulation of arachidonic acid metabolism in cells in culture. Proc. Natl. Acad. Sci. U. S. A. 76: 6632-6636.

40. Friedler, R. M., L. J. Belleau, J. A. Martino, and L. E. Earley. 1967. Hemodynamically induced natriuresis in the presence of sodium retention resulting from constriction of the thoracic inferior vena cava. J. Lab. Clin. Med. 69: 565-583.

41. Deen, W. M., C. R. Robertson, and B. M. Brenner. 1974. Glomerular ultrafiltration. Fed. Proc. 33: 14-20.

42. Gill, J. R., Jr., J. G. Frolich, R. E. Bowden, A. A. Taylor, H. R. Keiser, H. W. Seyberth, J. A. Oates, and F. C. Bartter. 1976. Bartter's syndrome: a disorder characterized by high urinary prostaglandins and a dependence of hyperreninemia on prostaglandin synthesis. Am. J. Med. 61: 43-51.

43. Donker, A. J. M., J. R. H. Bretjens, V. D. Hem, and L. Arisz. 1978. Treatment of the nephrotic syndrome with indomethacin. Nephron. 22: 374-381. 